\title{
CHEMICAL REMOVAL OF CONSERVATION SUBSTANCES BY 'SOXHLET'-TYPE EXTRACTION
}

\author{
Frank Bruhn ${ }^{1}$ • Alexander Duhr • Pieter M Grootes • Annette Mintrop • Marie-Josée Nadeau \\ Leibniz-Labor für Altersbestimmung und Isotopenforschung, Christian-Albrechts-Universität, Max-Eyth-Str. 11, \\ D-24118 Kiel, Germany
}

\begin{abstract}
At the Leibniz radiocarbon lab, art and archaeological objects, often chemically conserved and thus potentially contaminated with respect to their ${ }^{14} \mathrm{C}$ content, are treated using a computer-controlled "Soxhlet"-type series extractor. This device uses a continuous procedure of boiling and condensation of different solvents for extraction and vacuum filtration under constant process conditions. An elutrope sequence of five solvents that dissolve most customary conservation chemicals was selected. A study of these different contaminants applied to reference wood samples with subsequent accelerator mass spectrometry (AMS) measurements demonstrates that their effective removal is dependent on the use of adequate solvents. For many contaminants (e.g. wood glue, methyl cellulose, Klucel ${ }^{\circledR}$, sugar, and polyethylene glycol), routine acid-alkaliacid (AAA) treatment already yields satisfactory results, whereas for Caparol ${ }^{\circledR}$ and beeswax a relatively "mild" treatment with acetone, methanol, water, and subsequent standard AAA extraction is sufficient. Complete removal of rubber glue, epoxy resin, and paraffin can only be accomplished with our full set of solvents. The latter procedure is also appropriate when no or only incomplete information about the type of conservation material is available. For epoxy resin the contamination appears to be enriched in the alkali residue, and the easily soluble "humic acid" fraction, even after standard AAA treatment, gives satisfactory results. Two case studies on the application of the extraction procedures are presented.
\end{abstract}

\section{INTRODUCTION}

Chemical conservation of precious art and archaeological objects is a prerequisite for making these objects amenable to the researcher as well as to the interested public. A wide range of natural and artificially produced substances has been and is being applied for this purpose (Horie 1987). Determination of the age of the conserved objects is by no means simple because most organic chemicals used for conservation represent contamination for radiocarbon dating. They are either "dead" petroleum-based chemicals (e.g. paraffin), or have a "modern" ${ }^{14} \mathrm{C}$ content (e.g. beeswax), so that the measured age represents the time of conservation rather than the age of the object itself. These sources of foreign carbon can cause major dating problems as they are difficult or impossible to remove with the standard chemical sample cleaning techniques (AAA) used in many ${ }^{14} \mathrm{C}$ dating laboratories. Today, it should be common practice for restoration laboratories to conserve art objects with chemicals that can be easily removed or at least to keep a record of the treatment performed. Unfortunately, in the past this was not always the case and the work needed to obtain an accurate (and significant) age for the object can cause considerable headache to the dating laboratory. Obviously, in all cases contaminants have to be completely removed and sample pretreatment must therefore include extraction with a suite of organic solvents. This extraction procedure should on the one hand be rigorous enough to remove all potential contamination and on the other hand preserve the sample material.

\section{Principle and Equipment}

A soxhlet-type extraction efficiently removes contaminants with a low use of solvents and technician time. We have opted for a stepwise extraction using a "fexIKA 200 control" made by IKA ${ }^{\oplus}-$ Labortechnik, Germany. This 4-fold soxhlet-type apparatus is computer controlled and allows us to treat relatively small amounts of material.

${ }^{1}$ Corresponding author. Email: fbruhn@ @leibniz.uni-kiel.de.

(C) 2001 by the Arizona Board of Regents on behalf of the University of Arizona

RADIOCARBON, Vol 43, Nr 2A, 2001, p 229-237

Proceedings of the 17 th International ${ }^{14} \mathrm{C}$ Conference, edited by I Carmi and E Boaretto 
The device consists of an upper and a lower glass container, which are connected by a seal and a PTFE filter to hold the sample. The upper container is equipped with a cold finger to condense solvent vapor, and the lower container is placed in a heating/cooling block. During operation, the solvent used is placed in the lower container and heated to boiling. The increased pressure in the lower container forces the solvent vapors up through the filter. They condense upon contact with the cold finger and the sample simmers in the hot solvent in the upper container, stirred by gas bubbles, until all the solvent has been evaporated from the lower container. The heating block is then cooled, creating an underpressure in the lower container thus pulling the solvent and the extracted contaminants back through the sample and filter into the lower container. The operation is repeated under computer control a few times with fresh solvent derived from the evaporation until it is assumed that extraction with this solvent is complete.

In order to adapt the off-the-shelf system originally designed for extraction of pesticides from soil samples or determination of the oil content of oil seeds (Matthäus and Brühl 1999) to the routine extraction of small sample masses of as low as $10 \mathrm{mg}$ for AMS ${ }^{14} \mathrm{C}$ dating, some modifications to the seal had to be made:

- As the filter we use a $0.45 \mu \mathrm{m}$ pore size silver membrane that can be cleaned by pre-combustion at $500{ }^{\circ} \mathrm{C}$ and inserted with the sample in the combustion tube to avoid sample loss. This also minimizes the danger of dust particles adhering to the sample due to a highly electrostatic PTFE filter.

- To prevent contact between aggressive solvents and plastic parts, the connector between upper and lower containers holding the filter was modified so that only PTFE, glass, stainless steel, and the silver filter are in contact with the liquid.

- The new geometry leaves filter and sample freely accessible upon removal of the top container.

\section{The Elutrope Sequence}

Different conservation chemicals require different solvents for their removal. A general sample pretreatment procedure must therefore use a suite of solvents chosen to remove a broad range of organic chemicals. For these solvents not to act as contaminants themselves, it is important to remove them completely from the sample material by the end of the procedure. Since many solvents do not mix, they should be used in an elutrope sequence (Figure 1) where each subsequent solvent removes its predecessor until the final one can be removed by water. We started with a sequence of trichlorethylene, xylole, petroleumether, acetone, methanol, and water to remove potential contaminants based on laboratory practice. A refinement of the method now uses a partly modified suite of solvents (tetrahydrofurane, trichlormethane, petroleumether, acetone, methanol, water) in order to increase the versatility for the removal of different contaminants (especially paraffin and beeswax) and to avoid excess sample heating. Due to the lower boiling temperature of trichlormethane compared with xylole (61 versus ca. $140{ }^{\circ} \mathrm{C}$ ), the latter suite is of particular importance for the dating of bones where high extraction temperatures would potentially result in a loss of collagen.

\section{METHODS}

In order to test the effectiveness of the chemical extraction and to establish a routine procedure for the removal of conservation agents, $<5 \mathrm{~mm}$ pieces of oak wood from Grafrath/Germany with known age were soaked in the following conservation materials: rubber glue, wood glue, epoxy resin, methyl cellulose, Caparol ${ }^{\circledR}$, Klucel ${ }^{\circledR}$, sugar, polyethylene glycol (PEG), paraffin, and beeswax. The contaminated samples were then subjected to the following extraction procedures (cf. Figure 1): 


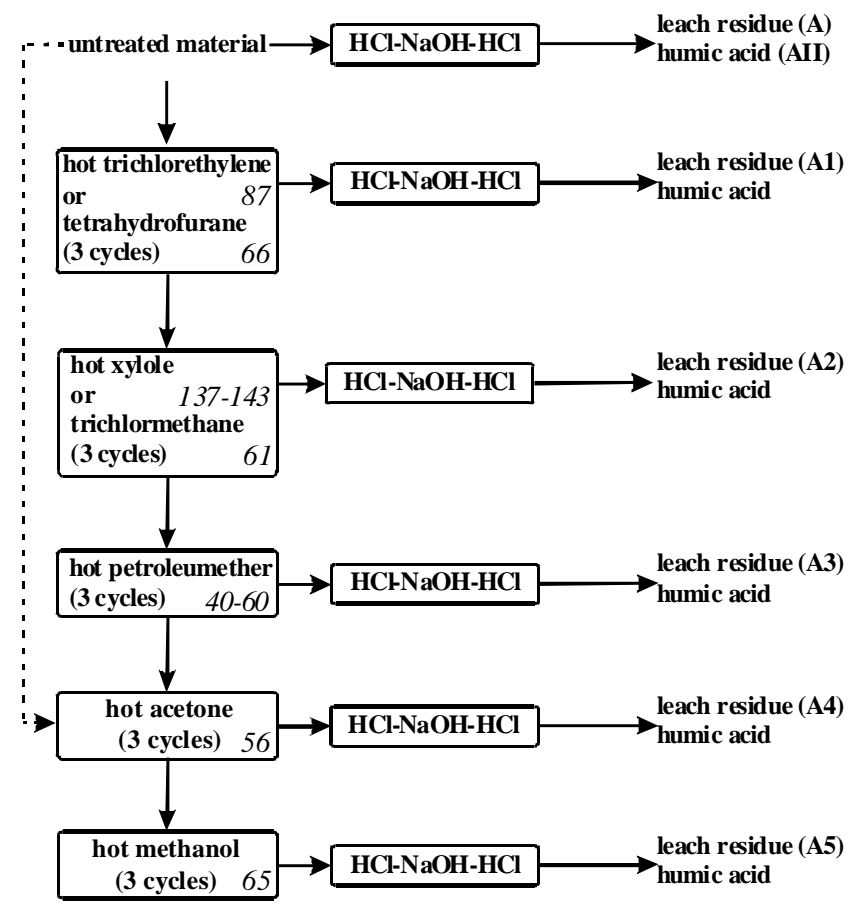

Figure 1 Exhaustive test series of our extraction procedure for strongly contaminated material. Numbers in italics are the boiling temperatures of the solvents in ${ }^{\circ} \mathrm{C}$. The dashed line denotes our "mild" extraction procedure, starting with acetone.

1. Standard AAA extraction, using $1 \% \mathrm{HCl}, 1 \% \mathrm{NaOH}$ and again $1 \% \mathrm{HCl}$ at $60{ }^{\circ} \mathrm{C}$. This procedure is routinely applied by many laboratories for removal of carbonates, fulvic and humic acids.

2. Hot extraction with acetone and methanol in three steps each and subsequent water treatment, followed by AAA extraction.

3. Hot extraction with trichlorethylene, xylole, petroleumether, acetone, methanol in three steps each and subsequent water treatment, followed by AAA extraction.

4. Hot extraction with tetrahydrofurane, trichlormethane, petroleumether, acetone, methanol in three steps each and subsequent water treatment, followed by AAA extraction.

All samples, treated and untreated, reference material as well as the conservation materials themselves were then combusted to $\mathrm{CO}_{2}$ in a closed quartz tube together with $\mathrm{CuO}$ and silver wool at $900{ }^{\circ} \mathrm{C}$. The $\mathrm{CO}_{2}$ was reduced to graphite with $\mathrm{H}_{2}$ at $600{ }^{\circ} \mathrm{C}$ on $2 \mathrm{mg}$ of iron catalyst. The iron/carbon mixture was pressed as a pellet into a target holder for the AMS measurement in a 3 MV Tandetron from High Voltage Engineering Europa (HVEE) with a single caesium sputter ion source and a separator/recombinator for simultaneous injection of the three isotopic carbon beams (cf. Nadeau et al. 1997, 1998).

The ${ }^{14} \mathrm{C}$ concentration of the samples was measured by comparing the simultaneously collected ${ }^{14} \mathrm{C}$, ${ }^{13} \mathrm{C}$, and ${ }^{12} \mathrm{C}$ beams of each sample with those of Oxalic Acid standard $\mathrm{CO}_{2}$ and coal background material. Conventional ${ }^{14} \mathrm{C}$ ages were calculated with a $\delta^{13} \mathrm{C}$ correction for isotopic fractionation based on the ${ }^{13} \mathrm{C} /{ }^{12} \mathrm{C}$ ratio measured in the AMS system simultaneously with the ${ }^{14} \mathrm{C} /{ }^{12} \mathrm{C}$ ratio. For 
determination of the measuring uncertainty (standard deviation $\sigma$ ), both the counting statistics of the ${ }^{14} \mathrm{C}$ measurement and the variability of the results from 8-10 intervals that, together, make up one measurement were observed. The larger of the two was adopted as the measuring uncertainty, and the error related to blank subtraction was added. The quoted $1 \sigma$ error is thus the best estimate for the full measurement and not just based on counting statistics.

\section{RESULTS AND DISCUSSION}

The age of the original, untreated reference wood, as determined by AMS- ${ }^{14} \mathrm{C}$ measurement, is $8385 \pm 35 \mathrm{BP}(1 \sigma)$ for the alkali residue and $8475 \pm 35 \mathrm{BP}(1 \sigma)$ for the humic acid. The apparent ages of the different conservation materials range from "dead" to modern (Table 1) which indicates that some of them are likely to cause significant age errors if they are not completely removed from the samples before AMS measurement. Contamination with respect to ${ }^{14} \mathrm{C}$ content in the case of standard AAA treatment is worst in the case of paraffin where the uncleaned sample yields an age of $16,570 \pm 70 \mathrm{BP}$ for the alkali residue.

Table $1{ }^{14} \mathrm{C}$ content and apparent ages of the conservation materials used

\begin{tabular}{lrc}
\hline Conservation material & \multicolumn{1}{c}{$\mathrm{pMC}$} & \multicolumn{1}{c}{ Age BP } \\
\hline Rubber glue $\left(\mathrm{UHU}^{\circledR}\right)$ & $10.85 \pm 0.10$ & $17,840 \pm 80$ \\
Wood glue & $0.43 \pm 0.04$ & $43,730+820 /-740$ \\
Epoxy resin & $47.35 \pm 0.22$ & $6005 \pm 35$ \\
Methyl cellulose $_{\text {Caparol}^{\circledR}}^{95.47 \pm 0.31}$ & $370 \pm 25$ \\
Klucel $^{\circledR}$ & $1.17 \pm 0.04$ & $35,750 \pm 280$ \\
Polyethylene glycol & $39.54 \pm 0.20$ & $7455 \pm 40$ \\
Paraffin & $0.00 \pm 0.03$ & $>58,800$ \\
Beeswax & $0.04 \pm 0.03$ & $>55,860$ \\
\hline
\end{tabular}

According to the pretreatment procedure necessary for complete removal of contaminants, the conservation materials can be divided into three different groups (Figure 2):

1 The $1 \sigma$ ranges of the alkali leach residues of wood glue, methyl cellulose, Klucel ${ }^{\circledR}$, sugar and PEG fall within $2 \sigma$ of the "true" age. This implies that these conservation agents can be adequately removed by standard AAA treatment, and "soxhlet" extraction is not necessary in these cases.

2. For Caparol ${ }^{\circledR}$ and beeswax, the alkali residues of the samples that were subjected to a relatively "mild" treatment with acetone, methanol, water, and subsequent standard AAA extraction already yield an age that is within $2 \sigma$ of the original wood, and the applied procedure is thus sufficient.

3. The rest of the investigated materials (i.e. rubber glue, epoxy resin and paraffin) requires the whole set of solvents for their complete removal. The refined method of using tetrahydrofurane instead of trichlorethylene and trichlormethane instead of xylole appears to be more suitable because ages within $2 \sigma$ of the original wood can be obtained from either the alkali residue or the "humic acid" fractions of samples treated with the above conservation material. Furthermore, the lower boiling temperature of trichlormethane compared to xylole makes easier handling of the extraction procedure and is of great potential use for the removal of contaminants from bone material where high temperatures could imply the risk of collagen loss. 
Table 2 Solubility for different conservation material in the extraction procedures used in this study. " + " = age of conservation material $( \pm 1 \sigma)$ is in the $2 \sigma$ range of the original wood; " $-"=$ age of conservation material $( \pm 1 \sigma)$ is beyond the $2 \sigma$ range of the original wood; "n.d." = not determined.

\begin{tabular}{|c|c|c|c|c|c|c|c|c|}
\hline \multirow[b]{2}{*}{$\begin{array}{c}\text { Conservation } \\
\text { material }\end{array}$} & \multicolumn{2}{|c|}{$\begin{array}{l}\text { Extraction } \\
\text { procedure } 1^{\mathrm{a}}\end{array}$} & \multicolumn{2}{|c|}{$\begin{array}{c}\text { Extraction } \\
\text { procedure } 2^{\mathrm{b}}\end{array}$} & \multicolumn{2}{|c|}{$\begin{array}{c}\text { Extraction } \\
\text { procedure } 3^{\mathrm{c}}\end{array}$} & \multicolumn{2}{|c|}{$\begin{array}{c}\text { Extraction } \\
\text { procedure } 4^{\mathrm{d}}\end{array}$} \\
\hline & Residue & $\begin{array}{l}\text { Humic } \\
\text { acid }\end{array}$ & Residue & $\begin{array}{l}\text { Humic } \\
\text { acid }\end{array}$ & Residue & $\begin{array}{l}\text { Humic } \\
\text { acid }\end{array}$ & Residue & $\begin{array}{c}\text { Humic } \\
\text { acid }\end{array}$ \\
\hline Rubber glue (UHU®) & - & + & - & n.d. & + & n.d. & - & + \\
\hline Wood glue & + & - & + & n.d. & - & n.d. & n.d. & n.d. \\
\hline Epoxy resin & - & + & - & n.d. & - & n.d. & - & + \\
\hline Methyl cellulose & + & - & + & n.d. & + & n.d. & n.d. & n.d. \\
\hline Caparol $^{\circledR}$ & - & - & + & n.d. & + & n.d. & n.d. & n.d. \\
\hline Klucel $^{\circledR}$ & + & + & + & n.d. & + & n.d. & n.d. & n.d. \\
\hline Sugar & + & + & + & n.d. & + & n.d. & n.d. & n.d. \\
\hline Polyethylene glycol & + & + & + & - & n.d. & n.d. & + & - \\
\hline Paraffin & - & - & - & + & - & - & + & + \\
\hline Beeswax & - & - & + & + & + & + & + & - \\
\hline
\end{tabular}

${ }^{\mathrm{a} A A A}$

bacetone, methanol, water, AAA

${ }^{c}$ trichlorethylene, xylole, petroleumether, acetone, methanol, water, AAA

${ }^{d}$ tetrahydrofurane, trichlormethane, petroleumether, acetone, methanol, water, AAA 


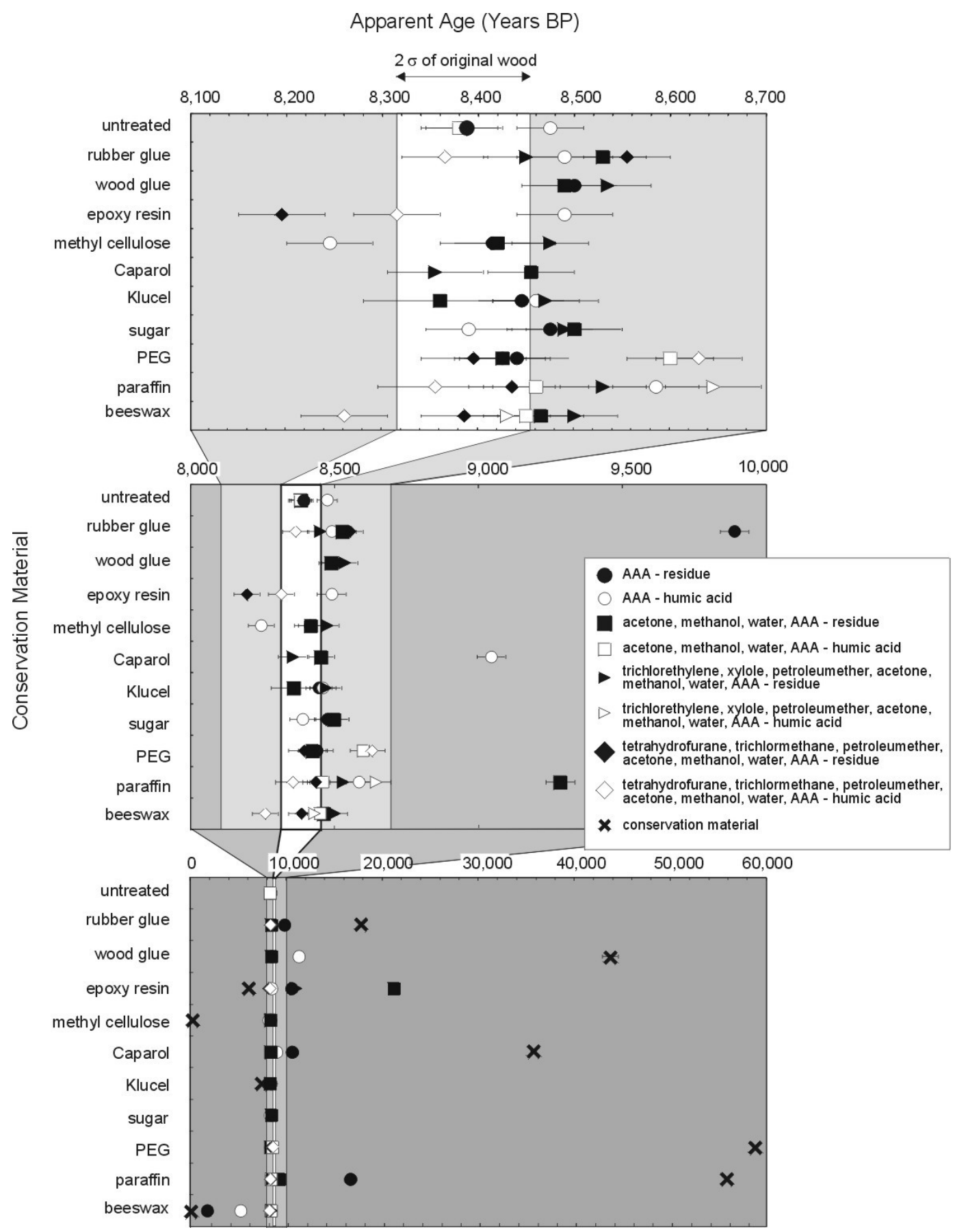

Figure 2 Results of a detailed study of the removal of different conservation substances applied to reference wood of known age (untreated) reveal that for many contaminants (wood glue, methyl cellulose, Klucel ${ }^{\circledR}$, sugar, polyethylene glycol) routine AAA treatment yields satisfactory results. Caparol ${ }^{\circledR}$ and beeswax require only a "mild" treatment, whereas rubber glue, epoxy resin and paraffin can only be removed with the wider range of solvents. 
Surprisingly, even epoxy resin could be removed although its cross-linked polymers are generally not soluble. However, they are swelled by some solvents, which enable the gel to be removed mechanically (Daniels 1981). In this case, as in the case of rubber glue, the fraction that falls within $2 \sigma$ of the original wood is the easily soluble "humic acid" fraction whereas the alkali residue apparently contains the major part of the insoluble conservation agent.

The results provide useful information for routine extraction procedures of "real" samples that have been conserved with a wide range of chemicals (Table 2). However, in case of missing or incomplete information about the conservation treatment, using the whole battery is the only reasonable modus operandi. For sets of similar samples, a minimum and thus economical extraction procedure may be developed by comparison of the data obtained from complete and "mild" extraction of a few samples, provided there is sufficient material available.

\section{Case Studies with Real Samples}

\section{${ }^{14} \mathrm{C}$ Dating of Two Ancient Wood Sculptures from a Bog Site}

Previous ${ }^{14} \mathrm{C}$ dating of two nearly three meters high wooden statues (male and female) of Germanic deities, which were found in the "Aukamper Moor" near Braak in the German state of SchleswigHolstein in 1946, placed the statues in the late Bronze Age. However, these measurements did not take fully into consideration the extensive conservation work done after their discovery. Notes made by the conservator mention a range of conservation substances, such as paraffin, tar, alcohol and oil. We investigated core samples drilled into the backs of the figures as well as wood shavings and performed AMS $-{ }^{14} \mathrm{C}$ measurement of the different fractions derived from a repeated complete extraction procedure (trichlorethylene, xylole, petroleumether, acetone, methanol, water). We also performed cellulose extraction on subsamples from both statues, applying the method described in Stuiver et al. (1984). The results (Figure 3) show that contaminants (e.g. paraffin in the female figure, with a measured apparent age of 51,060 $\pm 1100 \mathrm{BP}$ ) are only partly eliminated by conventional AAA extraction. They are, however, already effectively removed by the first extraction with trichlorethylene and xylole. In the male figure, the lower age of the untreated sample indicates contamination with younger substances. This is probably concealed by the large influence of the paraffin in the female sculpture. The core samples (D and E) were treated the same way as the A5 fraction, i.e. in one complete extraction procedure. The small age differences between them and the cellulose fractions (C) serve as a further proof of the effectiveness of the procedure. Our results for the core samples of both sculptures lie between $2185 \pm 30$ and $2315 \pm 30 \mathrm{BP}$, which is significantly younger than the results of previous conventional ${ }^{14} \mathrm{C}$ measurements and places the sculptures in the Iron Age of north-western Europe (< ca. 550 BC).

\section{A 6000-year-old Buddha?}

Figure 4 shows the results of AMS- ${ }^{14} \mathrm{C}$ measurements of samples from two conserved Buddha statues from the Southern Silk Route. There were no records of any conservation treatments being applied to these objects, and consequently we performed only standard AAA extraction. The obtained ages of $6300 \pm 30$ and $5045 \pm 60 \mathrm{BP}$ appeared completely unrealistic, in view of Buddha's birth date around $560 \mathrm{BC}$. Close microscopic inspection had revealed resin-like substances in the sample material, which were not used for dating. However, if these agents permeated the sample, they could still be responsible for the odd results. We subsequently performed solvent extraction of sample KIA5893, using a) the complete set of solvents (i.e. trichlorethylene, xylole, petroleumether, acetone, methanol, water), and b) a "mild" treatment, starting the extraction procedure with acetone. The latter procedure already resulted in much younger and more realistic ages. Yet, the age was still 
Figure 3 AMS- ${ }^{14} \mathrm{C}$ ages of different fractions of two ancient wood sculptures from a bog site. The fractions are derived from a repeated complete extraction procedure of samples from cores drilled from the backs of the figures as well as from wood shavings. The extraction was performed with the "old" set of solvents, i.e. trichlorethylene, xylole, petroleumether, acetone, methanol, water. "None" = direct combustion without chemical pre-treatment; A10 = leach residue after repeated extraction with the full set of solvents; A10II $=$ humic acid after repeated extraction with the full set of solvents; A10C $=$ cellulose extraction after repeated extraction with the full set of solvents; D, E = extraction of core samples with the full set of solvents and subsequent AAA treatment. For all other samples, see Figure 1. The dotted vertical lines delineate the averages of the alkali residues and cellulose after soxhlet treatment.

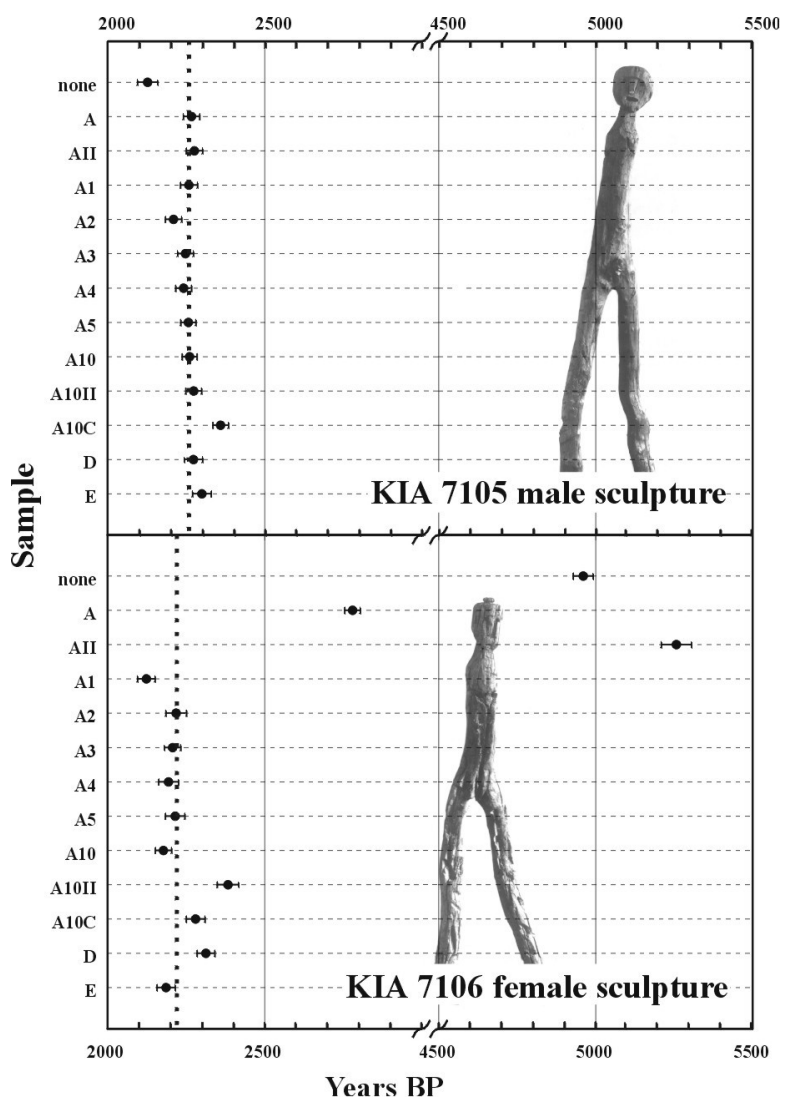

Figure $4{ }^{14} \mathrm{C}$ ages of samples from two Buddha statues from the Southern Silk Route after different pre-treatment procedures. The "complete extraction" was performed with trichlorethylene, xylole, petroleumether, acetone, methanol, water. 
significantly higher than the one with the complete organic extraction series. Consequently, the use of acetone, methanol and water alone did not remove completely the old contaminant. For the other sample (KIA5895), the measured age after the complete extraction agrees well with that of the humic acids obtained without solvent extraction. This indicates that the contaminant is not soluble in alkali, and the original humic acid fraction apparently was solely derived from the sample material. Together, the humic acid fraction and the completely extracted fraction provide a solid age for this sample.

\section{ACKNOWLEDGMENTS}

We thank Katja Harmel and Angelika Oriwall for operating the extraction system and Anke Rieck, Peter Hasselberg, and Malte Bitterling for their help in preparing the targets and performing the AMS measurements. The authors wish to acknowledge the help of Roland Aniol who performed the laborious standard PEG treatment of the sample wood, and the discussions with Roland Aniol, Mirja Dietrich, and Janet Ambers regarding the dated samples. We also thank the anonymous reviewer for thorough review of the paper and constructive suggestions.

\section{REFERENCES}

Daniels V. 1981. Removal of epoxy resins from antiquities. Conservation News 16:11.

Horie CV. 198. Materials for conservation: organic consolidants, adhesives and coatings. Oxford: Architectural Press. 281 p.

Matthäus B, Brühl L. 1999. Vergleich eines neuen Feststoff-Wirbelstrom-Extraktionsverfahrens mit der DGF-Standardmethode B-1\% (87) zur Bestimmung des Ölgehaltes von Ölsaaten. GIT LaborFachzeitschrift 2(99):151-5.

Nadeau M-J, Schleicher M, Grootes PM, Erlenkeuser H, Gottdang A, Mous DJW, Sarnthein JM, Willkomm H.
1997. The Leibniz-Labor AMS facility at the Christian-Albrechts-University, Kiel, Germany. Nuclear Instruments and Methods in Physics Research B123:2230.

Nadeau M-J, Grootes PM, Schleicher M, Hasselberg P, Rieck A, Bitterling M. 1998. Sample throughput and data quality at the Leibniz-Labor AMS facility. Radiocarbon 40(1):239-245.

Stuiver M, Burk RL, Quay PD. $1984 .{ }^{13} \mathrm{C} /{ }^{12} \mathrm{C}$ ratios in tree rings and the transfer of biospheric carbon to the atmosphere. Journal of Geophysical Research 89(D7):11,731-48. 